\title{
STANDARD FOR ECOLOGICAL SUSTAINABILITY OF REGIONAL LAND UTILIZATION BASED ON ECOLOGICAL FOOTPRINT: ESTABLISHMENT AND EMPIRICAL STUDY
}

\author{
LIU, Y. Z. ${ }^{1,2^{*}}-$ SUN, R. Z. ${ }^{1}-$ CHEN, Z. ${ }^{1}-$ CHEN, Y. ${ }^{1,2}-$ ZHANG, Z. ${ }^{3}-$ ZHU, X. N. ${ }^{1}-$ SONG, G. F. \\ - LI, Z. ${ }^{1}-$ WANG, Y. H. ${ }^{1}$ \\ ${ }^{I}$ School of Resources and Environment Engineering, Wuhan University of Science and \\ Technology, Wuhan 430081, China
}

${ }^{2}$ Hubei Key Laboratory for High-efficient Utilization and Agglomeration of Metallurgic Mineral Resources, Wuhan 430081, China

${ }^{3}$ College of Public Administration, Central China Normal University, Wuhan 430079, China

*Corresponding author

e-mail: Liuyanzhong@wust.edu.cn

(Received $11^{\text {th }}$ Jan 2019; accepted $8^{\text {th }}$ Mar 2019)

\begin{abstract}
The traditional ecological footprint model is found poorly applicable in the ecological sustainability assessment of regional land utilization. This paper designs a "consumption-output" ecological footprint model and establishes the standard for judging the ecological sustainability of regional land utilization with the sustainable ecological deficit of land as the assessment indicator. On this basis, this paper accounts and judges the ecological sustainability of land utilization in Linxiang City during the 2005-2013 period. The results showed: 1) The sustainable ecological deficit of the land in Linxiang City tended to grow amid fluctuation and remained at an ecological sustainability status; 2) The city has fully tapped the potential of available ecological capacity of cultivated land, pasture land and waters but has not made full use of that of construction lands and forest lands; 3) The ecological sustainability of regional land use is high in the north, low in the south and the weakest in the center. A comparison to the accounting results output from the traditional model shows that the improved model is more comprehensive and consistent with the reality in the assessment of ecological sustainability of regional land utilization. Finally, this paper provides corresponding suggestions for the city to realize ecological sustainability.
\end{abstract}

Keywords: sustainable ecological deficit, ecological capacity, consumption-output, regional ecological sustainability, the assessment criterion

\section{Introduction}

The indicator systems used for quantitative sustainability measurement have mushroomed, such as "drive-status-response" indicator system, sustainable economic welfare indicator, true development indicator and sustainability barometer, since the United Nations Conference on Environment and Development that took place in Rio de Janeiro, Brazil in 1992 (Xu and Zhang, 2000; Cha et al., 2013). Regional ecological sustainability means the long-term maintenance and development of the natural regional ecosystem as to the integrity of its structure and function (including supply of natural resources and ecosystem service) under the interference from nature and mankind (Peng et al., 2011, 2012). The natural ecosystem supports and regulates the life system of the earth and cannot be replaced by any artificial capital in this sense. Therefore, the concept of sustainability, which is derived from the concern over the depletion of natural resources and degradation of the ecological environment, can be realized only with regional ecological sustainability as an important condition precedent and basic way 
(Franke, 1996; Parris, 2003), and the essence of regional ecological sustainability is to coordinate mankind's demand and the ecological capacity. William Rees, a Canadian ecological economist, invented the ecological footprint approach in 1992, and his doctoral student Mathis Wackernagel has gradually refined the approach (Rees, 1992; Wackernagel and Rees, 1996; Wackernagel et al., 1999). The new approach reflects the utilization status of the ecosystem and assesses the ecological sustainability of regional land utilization through quantitative measurement of the gap between the mankind demand for the natural ecological service and the supply of the ecological service provided by nature (Xu et al., 2006). The approach has quickly become a hot research topic in the area of sustainability assessment and promoted many scholars to perform extensive empirical studies, due to its advantages, including novelty of theory, visualization of concept, enrichment of connotation, operability, easy acceptance and global comparability (Lenzen and Murray, 2001; Monfreda, 2004; Chen et al., 2008a, b; Zhao et al., 2012, 2014a, b; Xiong et al., 2003; Tian et al., 2015; Wei and Wu, 2011; He et al., 2011; Lu, 2011; Zhang et al., 2009; Dai and He, 2013; Liu et al., 2015; Lai and Huang, 2005).

However, according to most of the studies, when the traditional model is used to assess regional ecological sustainability, it is often found that if a region has a lower consumption level and less developed economy, it will be more sustainable, which, however, is obviously contrary to the sustainability theory. Some scholars have studied on how to improve the model:

(1) In 2003, Xiong Deguo proposed to classify the ecological footprint into the ecological footprint of consumption and that of production and measure the stress of human activities on the local ecosystem with the ecological footprint of output for the purpose of judging the sustainability of the regional ecosystem and reflect the fairness of regional development with the ecological footprint of consumption (Xiong et al., 2003). Tian Long has calculated and assessed the ecological sustainability of land utilization in the Northwest Region of China in 2012 by replacing the ecological footprint with that of production and using the adjusted balancing factor and the output factor (Tian et al., 2015). Though the concept of ecological footprint of output has been put forward, no scholars have explored the internal relation between the ecological footprint of consumption and that of production. Moreover, most of the researchers have used the monotonous resource account to perform the ecological footprint accounting in related researches, but the decision on what resource account is used is rather discretionary and less justifiable.

(2) Wei Yuan, He Feng and other researchers have introduced the ecological footprint index, ecological footprint intensity, ecological moderate population, ecosystem utilization efficiency and other indicators on the basis of the ecological footprint model to make the model more suitable for the assessment of ecological sustainability of land utilization (Wei and Wu, 2011; He et al., 2011). Chen Chunfeng, Zhao Guishen and Lu Xiaoli suggested combining the theory of energy value and ecosystem service value with the ecological footprint model (Chen et al., 2008a; Zhao et al., 2014a; Lu, 2011). The improved model combined with other indicators and approaches can measure to what extent does mankind consume natural resources in a more comprehensive and accurate manner, but it cannot accurately reflect the ecological sustainability of land utilization in a specific region, as it does not take into account the true resource consumption of the region. 
(3) Zhao Xingguo, Zhang Hengyi and Dai Yanan have adjusted and corrected the balancing factor and output factor based on the concept of "national hectare", "provincial hectare" and "regional hectare" respectively (Zhao et al., 2014b; Zhang et al., 2009). Compared to the traditional model, the improved model based on the balancing factor and output factor can reflect the actual condition of the research region with the calculation of ecological footprint and ecological capacity. However, it always measures the sustainability status of a region with the ecological footprint of consumption as a scale and ignores the biological output the research region can obtain from the ecosystem.

The concept of ecological footprint in the traditional model is actually the ecological footprint of consumption, namely, the area of the land with an ecological production required to satisfy the resource demand of the population in the region. What corresponds to the ecological footprint of consumption is the ecological footprint of output, that is, the area of the land with an ecological production needed to produce resources of the regional ecosystem. The traditional ecological footprint theory is based on the global perspective. The global ecosystem can be seen as a closed system with self-sufficiency, and the resource consumption of mankind is equal to the resource output of the ecosystem. Therefore, the ecological footprint of consumption can be used to measure the pressure of mankind activities on the global ecosystem and further asses the sustainability of the ecosystem. However, a region always imports and exports resources, so the pressure generated from the ecological footprint of consumption does not all come from inside the region and the pressure derived from the ecological footprint of output will not be fully borne by the region. Therefore, during the assessment of ecological sustainability of regional land utilization, either the ecological footprint of consumption or that of production cannot alone reflect the pressure of human activities on the regional ecosystem, and thus cannot accurately reflect the sustainability of the regional ecosystem. In recent years, Liu Yanzhong has designed the sustainable ecological deficit of land on the basis of the classified accounting for ecological footprints of consumption and output to reflect the extent of sustainable utilization of the regional ecosystem (Liu et al., 2015). However, they have not thoroughly analyzed the relation between the ecological footprints of "consumption-production" and the ecological capacity, which makes it unable to accurately reflect the sustainability statuses under different situations.

To sum up, the researches on the improvement and application of the ecological footprint model only make some technical upgrades to the model in part and can realize more precise accounting of ecological footprints. However, there are no reasonable, scientific and uniform standards for judging the ecological sustainability of regional land utilization, which will usually deliver a serious impact on accurate judgment of regional ecological sustainability and cause the assessment result to deviate from the actual condition. Therefore, it is particularly important to establish the standard for judging the ecological sustainability of regional land utilization.

Based on the analysis above, this paper will further explore the connotations of the ecological footprint of consumption, ecological footprint of output and ecological capacity as well as internal relations among them. Moreover, this paper will, based on the improved "consumption-production" ecological footprint model, establish the standard for judging the ecological sustainability of regional land utilization with the sustainable ecological deficit of land as the assessment indicator. On this basis, the paper accounts and judges the ecological sustainability of land utilization in Linxiang City. 


\section{Materials and methods}

\section{Introduction of traditional ecological footprint model}

The traditional ecological footprint model classifies various biological resources and energy consumption items required for human activities into the areas of six types of ecological production land (cultivated land, pasture land, forest land (including garden land), waters, fossil energy land and construction land), namely ecological footprint $(E F)$. Then, the model calculates the area of the land with an ecological production that can be provided by one region, namely, ecological capacity $(E C)$, and compares the difference between the $E C$ and the $E F$, namely, ecological surplus $(E R)$ or ecological deficit $(E D)$ to judge whether the region is sustainable.

\section{Improved "consumption-production" ecological footprint model}

\section{Analysis of connotations of related concepts}

The improved ecological footprint model classifies ecological footprints into ecological footprint of consumption $(E F c)$ and ecological footprint of output $(E F o)$. The $E F C$ assesses the extent to which the population in the region demand the area of the land with an ecological production from the perspective of resource consumption. As one region may import resources when the supply of resources cannot satisfy the consumption demand in the region, the $E F C$ can reflect the extent to which the region demands the ecological production land inside and outside the region, and this can be expressed in terms of the difference between the $E C$ and the $E F$, namely $E R c$ or $E D c$. The $E F o$ accounts the ecological footprint from the perspective of corresponding output in the consumption resource account. One region may export resources to other regions after satisfying the internal consumption demand, so the EFo reflects the extent to which the region and other regions demand the area of the land with an ecological production in the region, which represent the $E F C$ in broad sense. The difference between the EFo and the usable EC is the ERo or EDo, and the EDo represents the boundary of the ecological deficit borne by the regional ecosystem in the year. Specifically:

$$
\begin{gathered}
E F C=N r_{j} \sum\left(c_{i} / p_{i}\right) \\
E F o=N r_{j} \sum\left(o_{i} / p_{i}\right) \\
E C=N \sum\left(a_{j} r_{j} y_{j}\right) \\
E R c(E D c)=E C-E F C \\
E R o(E D o)=E F o-E C
\end{gathered}
$$

In the formulas: $N$ is the population size, $j$ is the ecological production land type $(j=1,2,3 \ldots 6), i$ is the "consumption-output" item type $(i=1,2,3 \ldots \mathrm{n}), r_{j}$ is the balancing factor, $c_{i}$ is the per capita consumption of item $i, o_{i}$ is the per capita output of item $i, p_{i}$ is the global average capacity for item $i, a_{j}$ is the per capita area of land type $j$, $y_{j}$ is the output factor. When the ecological capacity is calculated, a $12 \%$ biodiversity production area shall be deducted to protect the biodiversity. 


\section{Classification of ecological production land types}

In China, the land planning classifies lands into three tier-1 types, including (cultivated land, garden land, forest land and pasture land), construction land and other lands (including waters and nature reserves) in terms of purpose. Based on the characteristics of the land planning, this paper divides ecological production lands in the research region into seven types, namely, cultivated land, pasture land, forest land (including garden land), waters, fossil energy land, construction land and nature reserves (including unused grassland, alkaline land, marshland, sandy land, bare land and other unused lands). Nature reserves have important ecological values, and should be included in the ecological capacity calculation. However, these reserves do not directly provide human consumption products, so they can be excluded from the accounting of $E F C$ and $E F o$.

\section{Establishment of assessment indicators for ecological sustainability of land utilization}

Based on the relation between the consumption surplus/deficit and output surplus/deficit, this paper has designed the sustainable ecological deficit (EL) of land as the indicator that is used to assess the regional ecological sustainability and perform quantitative measurement of ecological sustainability. The EL represents the deficit in the area of the land with an ecological production the region can still withstand from the time point of research (Liu et al., 2015). For concrete formula, please see Section 1.4 "Standard for judging ecological sustainability of land utilization" in this paper.

\section{Establishment of standard for judging ecological sustainability of land utilization}

This paper has established the standard for judging the ecological sustainability under eight scenarios in two statuses, based on the analysis of the internal relations among the $E F C, E F o$ and $E C$ (see Table 1).

Status 1: If $E F o$ is less than $E C$, the region will not make full use of the $E C$ in the year, and the potential of the sustainable ecological deficit of the land will be the difference between the $E C$ and the $E F O$ in the region. Below is the calculation formula of $E L$ :

$$
E L=E C-E F C
$$

If: $E F c<E F o$, then: the region can export the ecological production land and display an ecological surplus. If: $E L>0$, then: the region will remain at an ecological sustainability status;

If: $E F c=E F o$, then: the region will have no ecological production land available for export and display an ecological balance. If: $E L>0$, then: the region will remain at an ecological sustainability status;

If: $E F O<E F C<E C$, then: the region will need to import the ecological production land and display an ecological deficit. If: $E L>0$, then: the region will remain at an ecological sustainability status;

If: $E F o<E F C=E C$, then: the region will need to import the ecological production land and display an ecological deficit. If: $E L=0$, then: the region will come at the critical point of ecological sustainability; 
If: $E F o<E C<E F c$, then: the region will need to import the ecological production land and display an ecological deficit. If: $E L<0$, then: the region will remain at an ecological non-sustainability status.

Table 1. Standard for judging ecological sustainability of regional land utilization based on "consumption-output" ecological footprint model

\begin{tabular}{|c|c|c|c|c|c|c|c|}
\hline & Status & Condition & $\begin{array}{c}\text { Import } \& \\
\text { export capacity }\end{array}$ & $\begin{array}{c}\text { Ecological } \\
\text { balance status }\end{array}$ & EL formula & $\begin{array}{c}\text { EL } \\
\text { value }\end{array}$ & $\begin{array}{c}\text { Annual } \\
\text { judgment of } \\
\text { sustainability }\end{array}$ \\
\hline \multirow{5}{*}{ 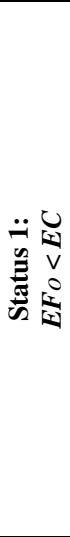 } & \multirow{5}{*}{$\begin{array}{l}\text { The region will not } \\
\text { make full use of the } \\
\text { EC in the year, and } \\
\text { the potential of the } \\
\text { sustainable } \\
\text { ecological deficit of } \\
\text { the land will be the } \\
\text { difference between } \\
\text { the EC and the EFo } \\
\text { in the region }\end{array}$} & (1) $E F c<E F o$ & $\begin{array}{c}\text { It can export } \\
\text { ecological } \\
\text { production land }\end{array}$ & $\begin{array}{l}\text { Ecological } \\
\text { surplus }\end{array}$ & \multirow{5}{*}{$E C-E F C$} & $E L>0$ & Sustainable \\
\hline & & (2) $E F c=E F o$ & $\begin{array}{l}\text { It cannot export } \\
\text { ecological } \\
\text { production land }\end{array}$ & $\begin{array}{l}\text { Ecological } \\
\text { balance }\end{array}$ & & $E L>0$ & Sustainable \\
\hline & & (3) $E F_{O}<E F_{C}<E C$ & $\begin{array}{l}\text { It must import } \\
\text { ecological } \\
\text { production land }\end{array}$ & $\begin{array}{c}\text { Ecological } \\
\text { deficit }\end{array}$ & & $E L>0$ & Sustainable \\
\hline & & (4) $E F O<E F C<E C$ & $\begin{array}{l}\text { It must import } \\
\text { ecological } \\
\text { production land }\end{array}$ & $\begin{array}{c}\text { Ecological } \\
\text { deficit }\end{array}$ & & $E L=0$ & $\begin{array}{c}\text { Critical point of } \\
\text { sustainability }\end{array}$ \\
\hline & & (5) $E F o<E C<E F c$ & $\begin{array}{l}\text { It must import } \\
\text { ecological } \\
\text { production land }\end{array}$ & $\begin{array}{l}\text { Ecological } \\
\text { deficit }\end{array}$ & & $E L<0$ & Unsustainable \\
\hline 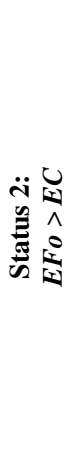 & $\begin{array}{l}\text { EF will be the } \\
\text { maximum footprint } \\
\text { the region can bear } \\
\text { in the year, the } \\
\text { potential of } \\
\text { available ecological } \\
\text { capacity will be } \\
\text { fully utilized, and } \\
\text { the corresponding } \\
\text { ecological deficit of } \\
\text { output will be the } \\
\text { maximum deficit } \\
\text { the region can } \\
\text { tolerate in the year }\end{array}$ & (1) $E F c<E F o$ & $\begin{array}{c}\text { It can export } \\
\text { ecological } \\
\text { production land }\end{array}$ & $\begin{array}{l}\text { Ecological } \\
\text { surplus }\end{array}$ & $E R o+(E C-E F c)$ & $E L>0$ & Sustainable \\
\hline
\end{tabular}

Status 2: If: $E F O>E C$, then: the $E F$ will be the maximum footprint the region can bear in the year, the potential of available ecological capacity will be fully utilized, and the corresponding ecological deficit of output will be the maximum deficit the region can tolerate in the year.

If: $E F c<E F o$, then: the region can export the ecological production land and display an ecological surplus. If: $E L>0$, then: the region will remain at an ecological sustainability status. Below is the calculation formula of EL:

$$
E L=E R o+(E C-E F C
$$

If: $E F c=E F o$, then: the region will have no ecological production land available for export and display an ecological balance If: $E L=0$, then: the region will come at the critical point of ecological sustainability. Below is the calculation formula of $E L$ :

$$
E L=E R o+E D c
$$


If: $E F c>E F o$, then: the region will need to import the ecological production land and display an ecological deficit. If: $E L<0$, then: the region will remain at an ecological nonsustainability status. The EL calculation formula is the same as formula (Eq. 8).

\section{Overview of research region}

As a county-level city under Yueyang City, Hunan Province, Linxiang lies along the border between Hunan Province and Hubei Province, covers a total land area of 1,743.68 square kilometers and supervises 19 towns. The terrain is high in the south and low in the north with diversified land utilization types, including serial mountains in the northeast part, continuous hills in the central part and vast low-altitude lakes in the northwest part. The city has abundant resources, including nonferrous metals, and products, including bamboo products, and was identified as a resource city by the State Council in December 2013. Resource cities constitute important strategic bases assuring China's energy and resource security and represent an important support for sustainable development of the national economy. A research on the assessment of ecological sustainability of land utilization in these cities is necessary to promote sustainable development of these cities, accelerate the transformation of the economic development pattern and construct a comprehensive well-off society. This paper will perform the empirical study based on Linxiang City, so the results will be representative, suitable and promising for application to some extent.

\section{Notes on calculation data}

The EFC and EFo of Linxiang City during 2005-2013 are calculated in accordance with the statistical yearbooks (2005-2013), overall land planning data (2006-2020) and land change data (2005-2013) of Linxiang City. This paper converts various "consumption-output" items of Linxiang City into the areas of 7 types of ecological production lands, where the "consumption-output" items of cultivated land include grains, beans, yams, oil seeds, cotton, hemps, sugar canes, vegetables and fruits, those of forest land include tea, camellia seeds, palm sheets, dry bamboo shoots and woods, those of pasture land include meats and poultry eggs, those of waters include aquatic products, those of construction land are mainly electric power, and those of fossil energy lands include coal, liquefied petroleum gas and gasoline.

The balancing factor and output factor used in the ecological footprint accounting are mainly the values of the traditional accounting model designed by Wackernagel (Rees, 1992; Wackernagel and Rees, 1996; Wackernagel et al., 1999). In detail, the output factor of cultivated land is defined as the ratio of the average productivity of the cultivated land in Linxiang City to that in the world, or 1.73. As to nature reserves, the balancing factor is defined as 0.12 (Lai and Huang, 2005), which is calculated with the balancing factor formula proposed by Lai Li for the unused land, and the output factor is set to 1 .

\section{Results}

\section{Analysis of ecological sustainability of land utilization in Linxiang City}

\section{Analysis of time series trend for ecological sustainability of land utilization}

The research has found (as shown in Table 2) that in Linxiang City, the aggregate ecological footprint of output always exceeded the aggregate available ecological capacity 
and kept growing at a faster speed than that of the aggregate available ecological capacity. During the 8-year period, the aggregate ecological footprint of output grew at an average speed of $5.47 \%$, which was higher than the annual average growth rate of $0.19 \%$ of the aggregate available ecological capacity and the aggregate ecological footprint of output at $2.42 \%$. As a result, the aggregate ecological balance of consumption changed from an ecological surplus in the beginning to an ecological deficit in 2012. However, the aggregate ecological footprint of consumption was still less than the aggregate ecological footprint of output, and the sustainable ecological deficit of the land in Linxiang City tended to grow amid fluctuation and always remained at an ecological sustainability status.

Table 2. Sustainable ecological deficit of Linxiang City in 2005-2013. (Unit: Ghm ${ }^{2}$ )

\begin{tabular}{c|c|c|c|c|c|c|c|c|c|c}
\hline Year & $\mathbf{2 0 0 5}$ & $\mathbf{2 0 0 6}$ & $\mathbf{2 0 0 7}$ & $\mathbf{2 0 0 8}$ & $\mathbf{2 0 0 9}$ & $\mathbf{2 0 1 0}$ & $\mathbf{2 0 1 1}$ & $\mathbf{2 0 1 2}$ & $\mathbf{2 0 1 3}$ & $\begin{array}{c}\text { Annual } \\
\text { average } \\
\text { growth } \\
\text { rate }\end{array}$ \\
\hline $\begin{array}{c}\text { Aggregate } \\
\text { available } \\
\text { ecological } \\
\text { capacity }\end{array}$ & 313516.82 & 314324.2 & 314677.59 & 314918.6 & 315419.88 & 316076.53 & 316742.82 & 317055.71 & 318218.38 & $0.19 \%$ \\
\hline $\begin{array}{c}\text { Aggregate } \\
\text { ecological } \\
\text { footprint of } \\
\text { consumption }\end{array}$ & 232016.89 & 245332.63 & 312281.29 & 252765.53 & 275107.04 & 310944.59 & 253813.23 & 317923.82 & 333521.87 & $5.47 \%$ \\
\hline $\begin{array}{c}\text { Aggregate } \\
\text { ecological } \\
\text { footprint of } \\
\text { output }\end{array}$ \\
\hline $\begin{array}{c}\text { Aggregate } \\
\text { ecological } \\
\text { profit/loss of } \\
\text { consumption }\end{array}$
\end{tabular}

\section{Characteristics of spatial arrangement for ecological sustainability of land utilization}

As illustrated in Figure $1 a$, the towns with strong sustainability included Huanggai Town, Chengfeng Town, Yuantan Town, Dinghu Town, Tandu Town, Wulipai Town, Yanglousi Town and Taolin Town, most of which lie in the central and northern parts of Linxiang City, in 2005. As illustrated in Figure $1 b$, the towns with strong sustainability included Huanggai Town, Jiangnan Town, Ruxi Town, Yuantan Town, Dinghu Town, Tandu Town, Nieshi Town and Taolin Town, most of which lie in the northern part of Linxiang City, in 2010. As illustrated in Figure 1c, the towns with strong sustainability included Huanggai Town, Jiangnan Town, Chengfeng Town, Ruxi Town, Yuantan Town, Dinghu Town, Tandu Town, Nieshi Town and Taolin Town, most of which lie in the northern part of Linxiang City, in 2013. Wulipai Town in the central part is a major town engaged in specialty agriculture and agricultural product processing as the pillar industry in the central economic zone of the city, Yanglousi Town is an important town 
along the border engaged in bamboo product and tea processing as the pillar industry, and the river plain area in the northern part is home to major towns specializing in agricultural production and aquatic breeding. High output is the major reason why these towns maintained strong ecological sustainability. In 2005-2013, the ecological footprint of consumption of Chang'an Sub-district was always far higher than its ecological footprint of output and available ecological capacity, and the sustainable ecological capacity of the region was always negative. This made the region always at an ecological non-sustainability status and indicated the region mainly mitigated its pressure by importing the ecological production land from the outside. This is mainly because Chang'an Sub-district, the downtown of Linxiang City, specializes in tourism and comprehensive light industries as the pillar industry and has an industrial structure with inadequate resources. Tourism and industrial production drive rapid growth of the ecological footprint of consumption, while the low resource output renders the ecological footprint of output and available ecological capacity unable to support the rapid growth of the ecological footprint of consumption.

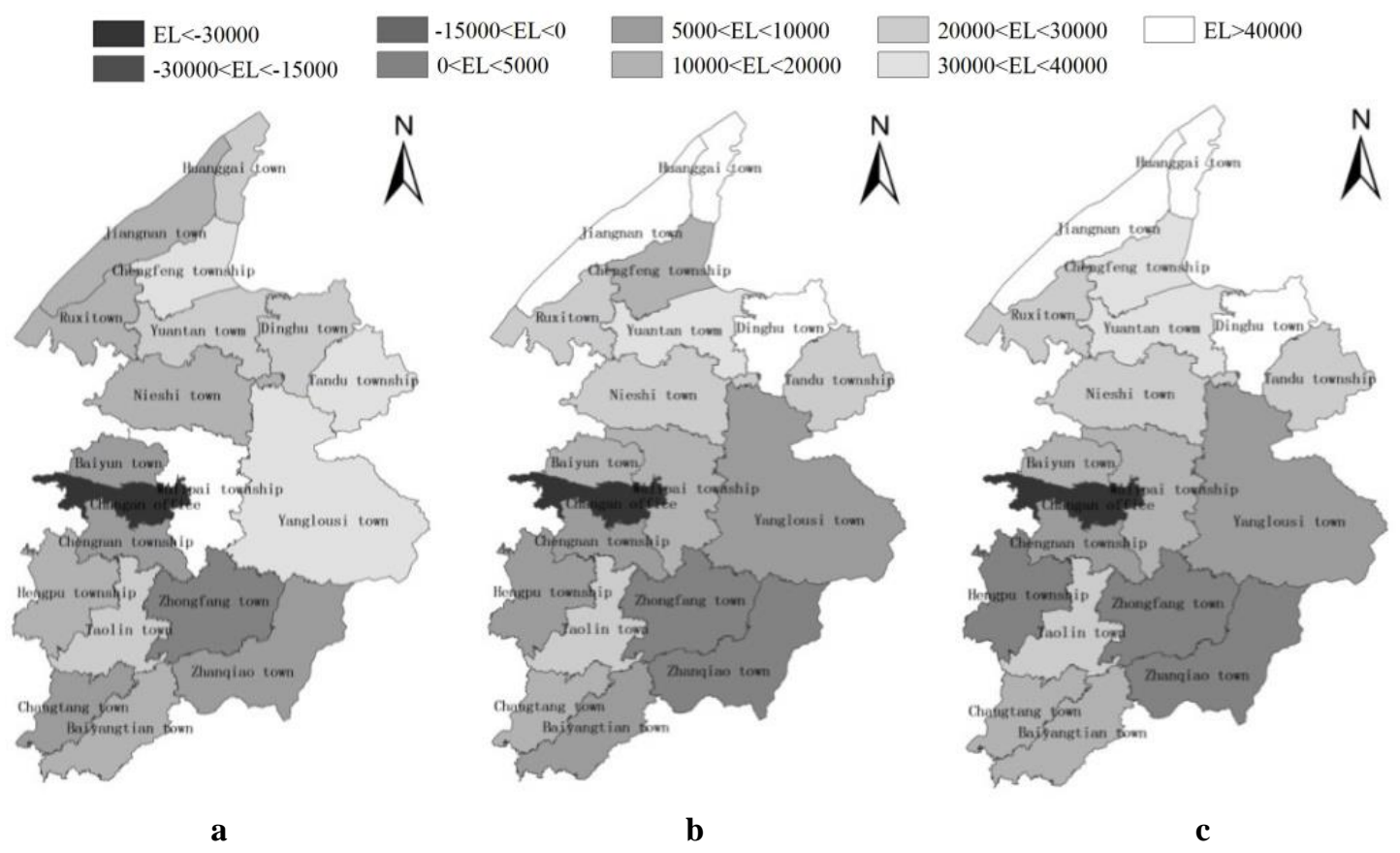

Figure 1. Spatial distribution of sustainable ecological deficit of Linxiang in a 2005, $\boldsymbol{b} 2010$ and $2013\left(\mathrm{Ghm}^{2}\right)$

\section{Analysis of ecological sustainability by land type}

It can be inferred from Table 3 that the ecological footprints of output of cultivated land, pasture land and waters all exceeded their available ecological capacities and ecological footprints of consumption over the years, indicating these three types of ecological production lands maintained an ecological surplus and could moderately export the output to mitigate the ecological sustainability pressure outside the region. These lands feature full use of their ecological capacity in the year, high utilization rate and high output ratio and kept ecologically sustainable with their sustainable ecological deficit above zero. 
Table 3. Composition of "consumption-output" ecological footprint lands. (Unit: Ghm²)

\begin{tabular}{|c|c|c|c|c|c|c|c|c|}
\hline \multicolumn{2}{|c|}{$\begin{array}{c}\text { Classification of ecological } \\
\text { production lands }\end{array}$} & \multirow{2}{*}{$\begin{array}{c}\begin{array}{c}\text { Cultivated } \\
\text { land }\end{array} \\
162536.11\end{array}$} & \multirow{2}{*}{$\begin{array}{c}\text { Pasture land } \\
5.1\end{array}$} & \multirow{2}{*}{$\begin{array}{c}\text { Forest land } \\
85017.54\end{array}$} & \multirow{2}{*}{$\begin{array}{l}\text { Waters } \\
2190.78\end{array}$} & \multirow{2}{*}{$\begin{array}{c}\begin{array}{c}\text { Construction } \\
\text { land }\end{array} \\
63609.66\end{array}$} & \multirow{2}{*}{\begin{tabular}{|c|}
$\begin{array}{c}\text { Fossil } \\
\text { energy land }\end{array}$ \\
0 \\
\end{tabular}} & \multirow{2}{*}{$\begin{array}{r}\begin{array}{l}\text { Nature } \\
\text { reserve }\end{array} \\
157.63\end{array}$} \\
\hline & $\begin{array}{c}\text { Available ecological } \\
\text { capacity }\end{array}$ & & & & & & & \\
\hline \multirow[t]{3}{*}{2005} & $\begin{array}{l}\text { Ecological footprint } \\
\text { of consumption }\end{array}$ & 101855.36 & 60328.35 & 270.26 & 32478.07 & 1471.18 & 35613.68 & 0 \\
\hline & $\begin{array}{c}\begin{array}{c}\text { Ecological footprint } \\
\text { of output }\end{array} \\
\end{array}$ & 210034.63 & 207716.31 & 25911.75 & 166689.66 & 2758.09 & 0 & 0 \\
\hline & $\begin{array}{l}\text { Available ecological } \\
\text { capacity }\end{array}$ & 162361.08 & 5.03 & 84635.6 & 2185.17 & 66737.28 & 0 & 152.37 \\
\hline \multirow[t]{3}{*}{2010} & $\begin{array}{c}\text { Ecological footprint } \\
\text { of consumption }\end{array}$ & 108430.82 & 72967.13 & 1538.78 & 35430.32 & 3562.81 & 89014.73 & 0 \\
\hline & $\begin{array}{l}\text { Ecological footprint } \\
\text { of output }\end{array}$ & 233407.77 & 231122.88 & 23199.91 & 187068.97 & 2785.71 & 0 & 0 \\
\hline & $\begin{array}{l}\text { Available ecological } \\
\text { capacity }\end{array}$ & 162997.5 & 5.03 & 84414.94 & 2183.95 & 68467.77 & 0 & 149.18 \\
\hline \multirow[t]{2}{*}{2013} & $\begin{array}{c}\text { Ecological footprint } \\
\text { of consumption }\end{array}$ & 159653.76 & 79003.71 & 992.3 & 38214.13 & 4546.25 & 51111.73 & 0 \\
\hline & $\begin{array}{l}\text { Ecological footprint } \\
\text { of output }\end{array}$ & 230487.79 & 240106.27 & 21418.29 & 237434.48 & 2464.56 & 0 & 0 \\
\hline
\end{tabular}

During the period, the ecological footprint of consumption of the construction land kept growing and gradually overtook the ecological footprint of output to suffer an ecological deficit. However, the ecological footprint of consumption was always lower than the available ecological capacity, and the sustainable ecological deficit of the land was always above zero, indicating the ecological sustainability of the land. However, the available ecological potential of the construction land was not fully tapped, and Linxiang City can increase the utilization rate of the construction land to offset the ecological deficit and promote ecological sustainability. During the period, the ecological footprint of output of the forest land was smaller than the ecological capacity and bigger than the ecological footprint of consumption, and the sustainable ecological deficit of the land was above zero, indicating the land was ecologically sustainable. Therefore, Linxiang City can export the ecological surplus of the forest land to mitigate the ecological sustainability pressure of the external regions and promote its economic development.

Linxiang City has no fossil energy land but sees growing demand for consumption of fossil energy. Therefore, the growing demand for the ecological production land of fossil energy should be satisfied by exporting ecological resources of the ecological production land. This has delivered a huge pressure on the ecological sustainability of the region. Nature reserves do not supply direct products for mankind consumption, so this paper will only consider their ecological capacity. During regional development, Linxiang City can moderately adjust land utilization types to improve the contribution of nature reserves to the ecological capacity.

\section{Comparison of assessment results output from the "consumption-output" ecological footprint model and traditional ecological footprint model}

This paper has analyzed the assessment indicators with the "consumption-output" ecological footprint model as shown in Table 2, and discovered the time series trend in the ecological sustainability of land utilization. The result show that the sustainable ecological deficit of Linxiang City arrived at the peak value in 2011, then started falling 
in the two years to follow but always remained above zero. This shows that Linxiang City has always maintained an ecological sustainable status, but the extent of ecological sustainability has tended to decline. Linxiang is a city with abundant mineral resources but only a few small mines are still under production after the Taolin Lead-Zinc Mine went bankruptcy. The Ruxi Tiger Mountain Large Tungsten Mine has not started formal mining and the resource exploration cannot continue. This which will definitely affect the economic and social development of the city and further affect the ecological sustainability of land utilization in the region. According to the assessment standard of the traditional ecological footprint model, Linxiang City started incurring an ecological deficit in 2012 and the deficit kept rising. This shows that the region is ecologically unsustainable, which is still changing for the worse. In 2013, Linxiang City was defined as a mature resource city by the State Council. The Sustainable Development Planning for National Resource Cities (2013-2020) defines a mature resource city as follows: "A mature resource city stays at the stable stage of resource exploitation, has strong capacity to assure resource security and high level of economic and social development and represents the core area that assures China's energy and resource security at the current stage". Yet, the traditional ecological footprint model assesses Linxiang City as ecologically unsustainable, which is inconsistent with the positioning as a mature resource city.

When analyzing the spatial distribution of ecological sustainability of land utilization, this paper compares the results output from the two models for the year 2013. As illustrated in Figure 1c, the "consumption-out" ecological footprint model has output the following results: The ecological sustainability of regional land use is high in the north, low in the south and the weakest in the central, the towns in the northern part are strong in ecological sustainability, those in the southern part are general, the central part is weak and the downtown Chang'an Sub-district is even unsustainable. It can be inferred from Figure 2 that the analysis results from the traditional model are bipolarized. The towns in the northern part are strong in ecological sustainability, those in the central and southern parts are not ecologically sustainable, and only a few towns maintain weak ecological sustainability. Figure 2 shows that Chang'an Sub-district, Zhongfang Town, Taolin Town, Zhanqiao Town and Changtang Town are all ecologically unsustainable, indicating that these towns must import ecological production lands to satisfy their excessive ecological footprint of consumption. In contrast, Zhongfang Town, Taolin Town, Zhanqiao Town and Changtang Town are major forces in the economic development engaged in mineral resource exploitation and processing, mining, construction material and personalized agricultural products as pillar industries. They all export ecological production resources, meaning that their ecological production lands can both satisfy their own development needs and help mitigate the external ecological pressure. The results from the "consumption-output" ecological footprint model show that the ecological footprints of output of Zhongfang Town, Taolin Town, Zhanqiao Town and Changtang Town are bigger than their ecological footprints of consumption, so these towns maintain an ecological surplus and can export ecological production lands. At the same time, the sustainable ecological deficits of these four towns are all above zero, indicating they are all ecologically sustainable. These results are more consistent with the actual conditions.

As far as the ecological sustainability of different land types is concerned, it can be inferred from the "consumption-output" ecological footprint model has output the results below (see Table 4). 
Table 4. Comparison of assessment results from the "consumption-output" ecological footprint model and traditional ecological footprint model. (Unit: $\mathrm{Ghm}^{2}$ )

\begin{tabular}{c|c|c|c|c|c|c|c|c}
\hline \multicolumn{2}{c}{$\begin{array}{c}\text { Classification of ecological } \\
\text { production lands }\end{array}$} & $\begin{array}{c}\text { Cultivated } \\
\text { land }\end{array}$ & Pasture land & Forest land & Waters & $\begin{array}{c}\text { Construction } \\
\text { land }\end{array}$ & $\begin{array}{c}\text { Fossil } \\
\text { energy land }\end{array}$ & $\begin{array}{c}\text { Nature } \\
\text { reserve }\end{array}$ \\
\hline 2005 & $\begin{array}{c}\text { "Consumption- } \\
\text { Output" model } \\
\text { Traditional model }\end{array}$ & 108179.27 & 147387.96 & 84747.28 & 134211.59 & 62138.48 & -35613.68 & 157.63 \\
2010 & $\begin{array}{c}\text { "Consumption- } \\
\text { Output" model } \\
\text { Traditional model }\end{array}$ & 124976.95 & 158155.75 & 83096.82 & 151638.65 & 63174.47 & -89014.73 & 152.37 \\
2013 & $\begin{array}{c}\text { OConsumption- } \\
\text { Output" model }\end{array}$ & 70834.03 & 161102.56 & 83422.64 & 199220.35 & 63921.52 & -51111.73 & 149.18 \\
\hline
\end{tabular}

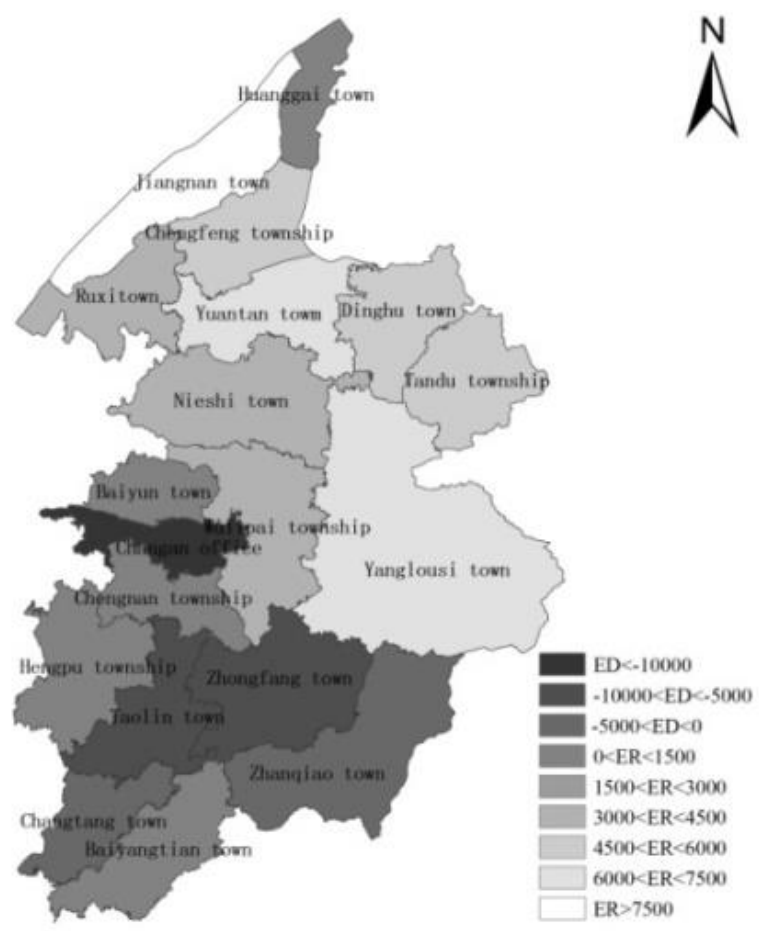

Figure 2. Spatial distribution of ecological surplus/deficit of Linxiang City in $2013\left(\mathrm{Ghm}^{2}\right)$

All the land types are ecologically sustainable, except that the sustainable ecological deficit of the fossil energy land is less than zero, indicating the land is ecologically unsustainable. According to the results from the traditional model, cultivated land, forest land, construction land and nature reserve all maintain an ecological surplus and are ecologically sustainable, while pasture land, waters and fossil energy land all record an ecological deficit and are ecologically unsustainable. Linxiang City has no fossil energy land but sees growing demand for consumption of fossil energy, so the fossil land is truly ecologically unsustainable. The ecological footprints of output of pasture land and waters are more than 3 times and about 6 times their ecological footprints of consumption in the years. This reveals that the biological resource outputs of pasture land and waters can fully satisfy the consumption demand in the region and reflects the status of ecological sustainability. This is because the traditional model measures the 
ecological capacity of the ecological production land based on the true area of the land and compares the capacity to the ecological footprint of consumption to judge the ecological sustainability of the land. However, this approach ignores the fact that the output of biological resources changes with the advance of production technologies and the change in the input level. In contrast, the "consumption-output" model measures the relations among the ecological footprint of consumption, ecological footprint of output and ecological capacity and assesses the ecological sustainability of land utilization with the sustainable ecological deficit as the indicator to make the result more consistent with the reality.

\section{Discussion}

Based on the improved "consumption-production" ecological footprint model, this paper has established the standard for judging the ecological sustainability of regional land utilization with the sustainable ecological deficit of land as the assessment indicator. On this basis, this paper has performed an empirical study based on Linxiang City and drawn the following basic conclusions through the analysis above:

(1) In Linxiang City, the ecological footprints of consumption mainly come from people's demand for cultivated land, pasture land, fossil energy land and waters, while cultivated land, pasture land and waters are principal contributors of ecological footprints of output. At present, cultivated land, pasture land and waters are all ecologically sustainable. However, as the ecological footprint of consumption keeps rising, the ecological surplus of the cultivated land will continuously decline and the ecological deficits of pasture land and waters will keep rising. The ecological footprints of output will grow annually, but the area of the lands with an ecological production will have a limited space for further expansion. Therefore, if mankind increases the output to satisfy the consumption without control, this will lead to the reduction of ecological capacity, ecological imbalance and other problems. To assure long-term sustainability of land utilization, Linxiang City should moderately implement intermittent suspension of farming, pasturing and fishing activities to recover the capacity of ecological production lands.

The construction land is ecologically sustainable in utilization, but its ecological footprint of output is far smaller than the ecological capacity. This reveals extensive utilization and low efficiency of the construction land. Therefore, Linxiang City should gradually lift the intensive utilization level of the construction land, and protect the areas of cultivated land and other lands with the function of ecological production to promote ecological sustainability of different types of lands.

The growing demand for fossil energy consumption has delivered a huge pressure on regional ecological sustainability. Linxiang City should consider reducing the use of fossil energies, develop green energies, encourage the production and use of energysaving products. At the same time, it should improve the utilization rate and cleanness rate of fossil energies.

(2) Due to different spatial distribution and functional positioning, the towns in the northern river plain area are high in ecological sustainability. Yet, restricted by the industrial structure and consumption mode, the ecological footprints of consumption of the towns in the central urban area have quickly grown and overtaken their ecological capacity. Therefore, these towns are low in ecological sustainability and even unsustainable. Linxiang City should pay attention to adjusting the industrial structure, 
optimizing the industrial arrangement and coordinating urban development and rural development, advocate sustainable consumption, and encourage the production and use of energy-saving products. It should save resources, develop the circular economy and protect the ecological environment. It should change the extensive economic development pattern, establish the production and consumption modes, intensive, economical and ecological, and promote the economic development to harmonize with resources and environment.

\section{Conclusion}

The "consumption-output" ecological footprint model is improved a lot as opposed to the traditional model as to suitability, integrity and reliability of the approach used to assess the ecological sustainability of regional land utilization. The analysis results based on the assessment indicators and judgment standards are more consistent with the reality and more reasonable than those from the traditional model.

This paper can to some extent solve the problem when the traditional ecological footprint model is employed to measure the ecological sustainability of regional land utilization. However, it is hard to collect related data used to calculate the balancing factor and output factor of ecological production lands. For this reason, these factors used in the research are both based on the "global hectare", which restricts the precision of the research to some extent. Related indicators fluctuate over a broad band, which also restricts easy understanding of the rule to some extent. In future, we will still need to strengthen the research on the values of these factors. However, these points are not the major topics of this paper. When the indicator $E L$ for ecological sustainability assessment of regional land utilization is applied to the horizontal comparison of ecological sustainability in different regions, the scientificity of comparative analysis will be affected by the difference of ecological footprint and ecological capacity. In other words, sustainable ecological deficit $(E L)$ can only preliminarily judge the absolute ecological sustainability of land, but can not quantitatively evaluate the extent of sustainable utilization of the regional land, which is valuable for follow-up research. And we will discuss these more in-depth during future studies.

Acknowledgements. This research supported by National Natural Science Foundation of China (71774066).

\section{REFERENCES}

[1] Cha, N., Wu, J. G., Yu, R. B. (2013): Analysis of subject trends in research on sustainable development. - Acta Ecological Sinica 33(9): 2637-2644.

[2] Chen, C. F., Wang, H. Y., Xiao, D. N. et al. (2008a): Comparison of sustainable development status in Heilongjiang Province based on traditional ecological footprint method and emergy ecological footprint method. - Chinese Journal of Applied Ecology 19(11): 2545-2549.

[3] Chen, C. Z., Lin, Z. S., Liang, R. J. (2008b): Analysis of ecological sustainability in China based on the ecological footprint method. - Journal of Natural Resources 23(2): 230-236.

[4] Dai, Y. N., He, X. G. (2013): Ecological sustainability in Chang-Zhu-Tan region: a prediction study. - Acta Ecological Sinica 33(2): 595-602. 
[5] Franke, T. T (1996): Making future landscapes: defining a path to qualified sustainability. - Landscape and Urban Planning 35(4): 241-246.

[6] He, F., Zhang, Q. F., Wang, L. et al. (2011): County-level ecological sustainability assessment based on improved ecological footprint model. - Transactions of the CSAE 27(5): 320-328.

[7] Lai, L., Huang, X. J. (2005): Assessment of ecological footprint of national general land use planning in China. - Transactions of the CSAE 21(2): 66-71.

[8] Lenzen, M., Murray, S. A. (2001): A modified ecological footprint method and its application to Australia. - Ecological Economics 37: 229-255.

[9] Liu, Y. Z., Zhou, X., Chen, Y. et al. (2015): Ecological footprint-based environmental impact assessment of structural adjustment objectives for overall land utilization planning - take Linxiang City as an example. - The Journal of Animal and Plant Sciences 25(3 Suppl. 1): 99-106.

[10] Lu, X. L. (2011): Ecological footprint model based on ecosystem services theory. Population-Resources and Environment 21(12): 115-120.

[11] Monfreda, C. (2004): Establishing national natural capital accounts based on detailed ecological footprint and biocapacity assessments. - Land Use Policy 21: 231-246.

[12] Parris, T. M., Kates, R. W. (2003): Characterizing a sustainability transition: Goals, targets, trends, and driving forces. US. - Proceedings of the National Academy of Sciences of the United States of America 100(14): 8068-8073.

[13] Peng, J., Wang, Y. L., Wu, J. S. et al. (2011): Research progress on evaluation frameworks of regional ecological sustainability. - Chinese Geographical Science 21(4): 496-510.

[14] Peng, J., Wu, J. S., Pan, Y. J. et al. (2012): Evaluation for regional ecological sustainability based on PSR model: conceptual framework. - Progress in Geography 31(7): 933-940.

[15] Rees, W. E (1992): Ecological footprint and appropriated carrying capacity: What urban economics leaves out. - UK Environment and Urbanization 4(2): 121-130.

[16] Tian, L., Zhang, Q. F., Zhang, X. et al. (2015): Assessment of ecological sustainability in northwest region based on improved ecological footprint model. - Journal of Arid Land Resources and Environment 29(8): 76-81.

[17] Wackernagel, M., Rees, W. E. (1996): Our Ecological Footprint: Reducing Human Impaction the Earth. - New Society Publishers, Gabriela Island.

[18] Wackernagel, M., Onisto, L, Bello, P. (1999): National natural capital accounting with the ecological footprint concept. - Ecological Economics 29: 375-390.

[19] Wei, Y., Wu, C. Y. (2011): Dynamic analysis of ecological sustainability based on ecological footprint model in Guizhou province. - Ecology and Environmental Sciences 20(1): 102-108.

[20] Xiong, D. G., Xian, X. F., Jiang, Y. D. (2003): Discussion on ecological footprint theory applied to regional sustainable development evaluation. - Progress in Geography 22(6): 618-626.

[21] Xu, Z. M., Zhang, Z. Q. (2000): Review indicators of measuring sustainable development. - Population Resources and Environment 10(2): 60-64.

[22] Xu, Z. M., Cheng, G. D., Zhang, Z. Q. (2006): A resolution to the conception of ecological footprint. - Population Resources and Environment 16(6): 69-78.

[23] Zhang, H. Y., Liu, W. D., Wang, S. Z. et al. (2009): Calculation and analysis of equivalence factor and yield factor of ecological footprint based on sub-national hectare: a case study of Zhejiang. - Journal of Natural Resources 24(1): 82-92.

[24] Zhao, G. S., Wang, Y. C., Tang, X. W. et al. (2014a): Evaluation of sustainability for intensive farmland ecosystem based on energy ecological footprint. - Transactions of the CSAE 30(18): 159-167. 
[25] Zhao, H. H., Wang, Y., Gu, X. M. et al. (2012): Establishment of environmental sustainability assessment indicators based on material flow and ecological footprint model in Tongling City of Anhui Province. - Acta Ecologica Sinica 32(7): 2025-2032.

[26] Zhao, X. G., Pan, Y. J., Ding, S. et al. (2014b): Evaluation of regional land use sustainability and its spatial-temporal pattern among provinces in China. - Transactions of the Chinese Society of Agricultural Engineering 30(3): 196-204. 